\title{
The Epidemiologic Vocabulary of the West and the Former Soviet Union: Different Sides of the Same Science
}

\author{
Anna Grigoryan*1, Carmen Clarke², Lyudmila Zueva³, Tetyana Chumachenko ${ }^{4}$, Edmond F. \\ Maes $^{1}$ and Bonnie Smoak ${ }^{2}$
}

${ }^{1}$ CDC, Atlanta, GA, USA; 'WRAIR, Silver Spring, MD, USA; ${ }^{3}$ North-Western State Medical University after I.I. Mechnikov, St.Petersburg, Russian Federation; ${ }^{4}$ Kharkiv National Medical University, Kharkiv, Ukraine

\section{Objective}

The purpose of this project was to develop an English-Russian Epidemiology Dictionary, which is needed for improved international collaboration in public health surveillance.

\section{Introduction}

As part of the US Department of Defense strategy to counter biological threats, the Defense Threat Reduction Agency's Cooperative Biological Engagement Program is enhancing the capabilities of countries in the former Soviet Union (FSU) to detect, diagnose, and report endemic and epidemic, man-made or natural cases of especially dangerous pathogens. During these engagements, it was noted that Western-trained and Soviet-trained epidemiologists have difficulty, beyond that of simple translation, in exchanging ideas.

The Soviet public health system and epidemiology developed independently of that of other nations. Whereas epidemiology in the West is thought of in terms of disease determinants in populations and relies on statistics to make inferences, classical Soviet epidemiology is founded on a more ecological view with the main focus on infectious diseases' spread theory. Consequently many fundamental Soviet terms and concepts lack simple correlates in English and other languages outside the Soviet sphere; the same is true when attempting to translate from English to Russian and other languages of the FSU. Systematic review of the differences in FSU and Western epidemiologic concepts and terminology is therefore needed for strengthening understanding and collaboration in disease surveillance, pandemic preparedness, response to biological terrorism, etc.

\section{Methods}

Following an extensive search of the Russian and English literature by a working group of Western and FSU epidemiologists, we created a matrix containing English and Russian definitions of key epidemiologic terms found in FSU and Western epidemiology manuals and dictionaries, such as A Dictionary of Epidemiology (1), Epidemiology Manual (2) and many other sources. Particular emphasis was placed on terms relating to infectious disease surveillance, analysis of surveillance data, and outbreak investigation. In order to compare the definitions of each term and to elucidate differences in usage and existing gaps, all definitions were translated into English and Russian so that the definitions could be compared side by side and discussed by the working group.

\section{Results}

Six hundred and thirty one terms from 27 English and 51 Russian sources were chosen for inclusion based on their importance in applied epidemiology in either the West or the FSU. Review of the definitions showed that many terms within biosurveillance and infectious disease public health practice are used differently, and some concepts are lacking altogether in the Russian or English literature. Significant gaps in FSU epidemiology are in the areas of biostatistics and epidemiologic study designs. There are distinctive differences in FSU and Western epidemiology in the conceptualization and classification of disease transmission, surveillance practices, and control measures.

\section{Conclusions}

Epidemiologic concepts and definitions significantly differed in the FSU and Western literature. To improve biosurveillance and international collaboration, recognition of these differences must occur. Detailed analysis of epidemiology terminology differences will be discussed in the presentation and paper. Major limitations of the work were scarcity of prior research on the subject and lack of bilingual epidemiologists with the good understanding of FSU and Western approaches. A bilingual reference in the form of a dictionary will greatly improve mutual comprehension and collaboration in the areas of biosurveillance and public health practice.

\section{Keywords}

Surveillance; Dictionary; Collaboration

\section{References}

1. Porta Miquel. A Dictionary of Epidemiology, Fifth Edition, Oxford university press, USA, 2008

2. Zueva L.P.Yafaev P.Kh. Epidemiology: Manual. "Foliant publishers", Russia, 2005.

\section{*Anna Grigoryan}

E-mail: Ffg7@cdc.gov 